TRABAJOS DE PREHISTORIA

70, N. ${ }^{\circ} 1$, enero-junio 2013, pp 95-113, ISSN: 0082-5638

doi: $10.3989 /$ tp.2013.12104

\title{
La explotación tartésica de la casiterita entre los ríos Tajo y Guadiana: San Cristóbal de Logrosán (Cáceres)
}

\author{
Tartessian cassiterite exploitation between the Tajo and Guadiana rivers: San Cristóbal \\ de Logrosán (Cáceres)
}

\author{
Alonso Rodríguez Díaz (*) \\ Ignacio Pavón Soldevila (*) \\ David M. Duque Espino (*)
}

\section{RESUMEN}

El objetivo de este trabajo es ofrecer una síntesis de la investigación arqueológica y arqueominera realizada entre 1998 y 2000-2002 en el Cerro de San Cristóbal de Logrosán (Cáceres). Esta permite proponer una probable 'cadena operativa' del beneficio de la casiterita en este lugar durante el tránsito Bronce Final-Periodo Orientalizante. La gestión e imbricación del mineral en las relaciones Tajo-Guadiana y en los circuitos atlántico-mediterráneos confluyentes en el Suroeste de la Península Ibérica parecen justificar, entre otras razones, la temprana integración del actual territorio extremeño en Tartessos. La investigación en Logrosán y la arqueología del estaño se vieron bruscamente interrumpidas por el inesperado fallecimiento de su principal impulsor, Craig Merideth. Su continuidad pretende canalizarse a través de la reciente declaración del Cerro de San Cristóbal como "geositio" del Geoparque "Ibores-Villuercas-Jara" y del proyecto del Plan Nacional I+D +i El tiempo del tesoro de Aliseda, entre cuyas acciones se encuentra la prospección arqueominera del oeste de la penillanura cacereña realizada en 2011.

\footnotetext{
ABSTRACT

The objective of this work is to offer a synthesis of the archaeological and archaeo-mining investigation

(*) Área de Prehistoria, Facultad de Filosofía y Letras, Universidad de Extremadura. Campus Universitario s/n. 10071 Cáceres. Correos e.: alonso@unex.es; ipavon@unex.es; despino@unex.es

(**) Université Rennes 2-Haute Bretagne, Département Langues Etrangères Appliquées. Place du Recteur Henri Le Moal CS 24307. 35043 Rennes Cedex. France.

Correo e.: moises.poncedeleon@uhb.fr

(***) C/ Jiménez Aranda 6. Apartamento 34. 41018 Sevilla. Correo e.: mhunt@us.es

Recibido 20-II-2012; aceptado 28-V-2012.
}

\author{
Moisés Ponce de León Iglesias (**) \\ Mark A. Hunt Ortiz (***) \\ Craig Merideth (+)
}

carried out in recent years (1998 and 2000-2002) in the Cerro de San Cristobal site, Logrosán (Cáceres). The results allow us to propose a chaîne opératoire for the cassiterite treatment and use in Cerro de San Cristóbal during the transition from the Late Bronze Age to the Orientalizing period. The management and role of this mineral in the Tajo-Guadiana relations and in the Atlantic-Mediterranean circuits meeting in the Southwest of the Iberian Peninsula, together with other factors, seems to justify the early integration of the territory of Extremadura in Tartessos. The investigation in Logrosán and the archaeology of tin were suddenly interrupted by the unexpected death of its main promoter, Dr. Craig Merideth. The continuation of this project is now to be channelled through the recent declaration of the Cerro de San Cristobal as a 'geosite' in the 'Ibores-VilluercasJara Geopark' and through the National Research, Development and Innovation Scheme's project El tiempo del tesoro de Aliseda, among whose actions is the archaeomining survey from the West of the peneplain of Cáceres made in 2011.

Palabras clave: Península Ibérica; Extremadura; Logrosán, Bronce Final-Orientalizante; Tartessos; Siglos VIIIVI a.C.; Asentamiento minero; Prospección arqueominera; Metalurgia; Casiterita; Estaño.

Key words: Iberian Peninsula; Extremadura; Logrosán; Late Bronze Age-Orientalizing; Tartessos; VIII-VI centuries B.C.; Mining settlement; Archaeomining survey; Metallurgy; Cassiterite; Tin.

\section{INTRODUCCIÓN}

El estudio de la minería prehistórica en la Península Ibérica siempre ha ofrecido dificultades por muy diferentes razones. En la última década, 
a la revisión de los pocos casos conocidos, se han unido otros, casi siempre fruto de prospecciones geo-mineras, que han completado algo más el panorama y enriquecido algunas síntesis publicadas en los últimos años (Montero Ruiz 2010: 59). Pese a ello, no es posible reconocer, por el momento, la letra pequeña de buena parte de la actividad extractiva y de la explotación de los minerales de cobre, la plata y el oro. Ello se agrava, si cabe, cuando se trata de dilucidar la minería del estaño, percibida por los especialistas como un verdadero 'problema' en el escenario europeo (Giumlia-Mair y Lo Schiavo 2003). En la Península Ibérica, se ha planteado un primer aprovechamiento -al parecer más intensivo de lo que se venía pensando- de las menas de cobre-estaño naturalmente aleadas (Rovira Lloréns y Montero Ruiz 2003). En cambio, siguen siendo muy poco conocidos los pormenores de la explotación del estaño que se ofrece de forma aislada, es decir, del que se emplearía mayoritariamente en las aleaciones 'culturales' de la Prehistoria Reciente y la Protohistoria. Ingrediente este, dicho sea de paso, de una metalurgia con escasos subproductos documentados (Rovira Lloréns y Renzi 2010: 109).

La discusión sobre esas formas de explotación del estaño en la Prehistoria Reciente peninsular ha pivotado en gran medida sobre las alusiones de las fuentes clásicas a su aprovechamiento en el mundo antiguo. Así, siguiendo las muy conocidas citas de Estrabón (Libro 3, 2, 9), dichas actividades debían ir desde su beneficio en depósitos superficiales a partir del lavado de arenas: "entre los ártabros que viven en la parte más alejada del septentrión y del occidente de Lusitania el suelo contiene, según aseguran, eflorescencias de plata, estaño y oro blanco mezclado con plata; esta tierra es arrastrada por los ríos, y las mujeres, una vez amasada la arena, la lavan en tamices tejidos en forma de cesta", -como se ha defendido desde la Arqueología en alguna ocasión (Luzón Nogué 1983) - hasta la propia excavación: "pero el estaño, dice Posidonio, no se encuentra en la superficie de la tierra, como aseguran en repetidas ocasiones los historiadores, sino excavando, y se produce tanto en la región de los bárbaros que habitan más allá de los lusitanos, como en las Cassitérides".

El objetivo de este artículo es, precisamente, dar a conocer las novedades que sobre esta segunda modalidad referida por Estrabón vienen aportando los trabajos arqueológicos desarrollados durante la última década en el poblado minero-metalúrgico del Cerro de San Cristóbal de Logrosán (Cáceres), fechado en la transición Bronce Final-Orientalizante y representativo de la minería tartésica del estaño (Sos Baynat 1977; Merideth 1998a, 1998b; Rodríguez Díaz et al. 2001). El eje que lo articula se inspira en Rodríguez Díaz et al. (1). Como complemento y contexto de todo ello se aportan los resultados de la prospección geológica y arqueominera realizada en junio-julio de 2011 en el sector centrooccidental de la penillanura cacereña, un conocido ámbito de concentración estannífera de la región extremeña (Florido Laraña 1987; Locutura Rupérez y Alcalde Molero 2007).

\section{EL CERRO DE SAN CRISTÓBAL: MARCO GEOGRÁFICO E HISTORIOGRAFÍA}

El Cerro de San Cristóbal, "geositio" del recientemente declarado Geoparque "VilluercasIbores-Jara" (Chicharro et al. 2011), es una imponente elevación granítica (684 m.s.n.m.) de orientación SO-NE, situada prácticamente en la divisoria de aguas Tajo-Guadiana. Emerge en la planicie suavemente alomada que se abre al sursuroeste de las sierras de Villuercas y se prolonga sin dificultad hasta el valle del Guadiana (Florido Laraña 1987: 73) (Fig. 1). El río Ruecas -que nace cerca de Logrosán y desemboca en el Guadiana no lejos de Medellín- es el principal curso fluvial que conecta ambas comarcas, discurriendo a lo largo de un recorrido desarbolado y muy transformado por la acción humana a lo largo del tiempo. El cerro alberga abundantes filones mineralizados en casiterita, un potencial que se añade a su singularidad geomorfológica y biogeográfica $\mathrm{y}$ fundamenta su interés arqueominero.

(1) Alonso Rodríguez Díaz, Ignacio Pavón Soldevilla, David. M. Duque Espino y Craig Merideth. Póster "El factor minero-metalúrgico en la Protohistoria extremeña: la explotación de casiterita en Logrosán (Cáceres)", presentado en el Meeting Archaeometallurgy: technological, economic and social perspectives in late prehistoric Europe. TESME (Madrid, 25-27 de noviembre de 2009) en homenaje a Salvador Rovira. 


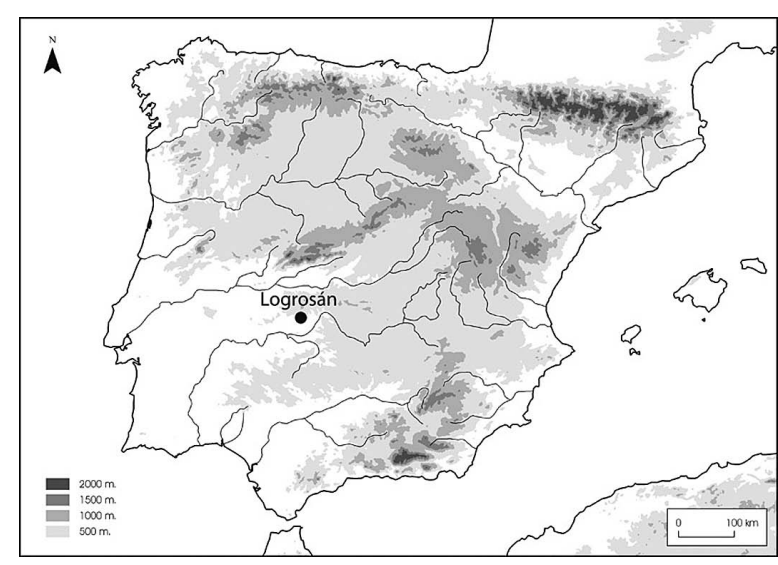

Fig. 1. Localización del poblado minero-metalúrgico del Cerro de San Cristóbal de Logrosán (Cáceres) en la Península Ibérica. Se fecha en la transición Bronce Final-Orientalizante.

\subsection{Geología y aproximación paleobiogeográfica}

El Cerro de San Cristóbal es un relieve residual heredado de un paisaje modelado durante el Mesozoico. Tiene este stock granítico poco más de $2 \mathrm{~km}^{2}$, una forma groseramente elipsoidal en dirección N65E y mide 2,6 km por $1 \mathrm{~km}$ (Fig. 2A). La facies principal es un granito adamellítico de grano grueso con tendencia porfídica de dos micas. Las facies de variación son granitos adamellíticos de grano fino de dos micas con zonas en las que puede estar ausente la biotita. Los contactos entre las diferentes facies son graduales y difusos (Moreno et al. 2004).

El cuerpo granítico se emplaza en los materiales metasedimentarios del Grupo Domo Extremeño, serie inferior del Complejo Esquisto Grauváquico, en las facies de grauvacas y lutitas con capas de conglomerados intraformacionales de edad Precámbrico superior. En la periferia del macizo, $1 \mathrm{~km}$ de anchura, estos materiales han sufrido un metamorfismo de contacto, transformándose en corneanas con cordiertita ( \pm andalucita) en las rocas más cercanas al cuerpo granítico. Su intensidad disminuye progresivamente, pasando a pizarras mosqueadas a medida que nos alejamos del contacto. Los mapas gravimétricos regionales sugieren que el cuerpo granítico se prolonga en profundidad bajo la cobertura metamórfica (Moreno et al. 2004). El stock de Logrosán ocupa, pues, una posición apical con respecto a un macizo de mayores de dimensiones oculto bajo las series metasedimentarias. El emplazamiento del stock granítico es sincinemático con las fases de plegamiento que han deformado el encajante metamórfico, adaptándose la esquistosidad principal de las rocas encajantes a la forma del macizo.

La mineralización estannífera se asocia a filones de cuarzo intragraníticos cuya anchura va de algunos milímetros a $70 \mathrm{~cm}$ que se agrupan en haces filonianos más o menos densos separados por zonas estériles. Los haces filonianos de direcciones N30E o N50E tienen pendientes de $70^{\circ}$ Oeste. Su emplazamiento fue verosímilmente contemporáneo con el de la mineralización ligada a los procesos hidrotermales de la zona apical de una cúpula granítica, cicatrizando fracturas con desplazamiento horizontal y grietas de tensión asociadas. Se han reconocido, en la mitad occidental del macizo, cuatro conjuntos de haces filonianos de 20 a $50 \mathrm{~m}$ de anchura separados por zonas estériles de entre 50 y 150 $\mathrm{m}$. El desarrollo longitudinal de los haces varía entre 100 y $500 \mathrm{~m}$. Los filones van acompañados de una alteración hidrotermal del encajante en bandas de greisenificación, turmalinización y silicificación, paralelas a las salbandas de los filones y de anchura inferior a $10 \mathrm{~cm}$. La mineralización en casiterita se encuentra sobre todo en el interior de los filones pero puede estar también diseminada en el greisen de la alteración hidrotermal (Rossi 1975). Las asociaciones minerales que se encuentran en los filones son: casiterita \pm arsenopirita \pm estannina y como accesorios calcopirita \pm molibdenita \pm pirrotina \pm bismutina \pm bismuto nativo \pm pirita \pm esfalerita en una ganga de cuarzo con \pm moscovita y turmalina (Rossi, 1975; Moreno et al. 2004; Locutura Rupérez y Alcalde Molero 2006). La presencia de wolframita es excepcional (Rossi, 1975, Gumiel y Arribas 1990).

Otros haces de filones o filones individuales de escasa importancia son visibles en la mitad oriental del stock y han sido objeto de labores muy superficiales de escasa entidad. A $1 \mathrm{~km}$ al sur del stock granítico las formaciones coluvioaluvionares recientes, procedentes de la erosión del relieve residual del Cerro San Cristóbal, han dado lugar a la formación de placeres detríticos con concentraciones ricas en casiterita (y oro) que han sido también objeto de labores. 

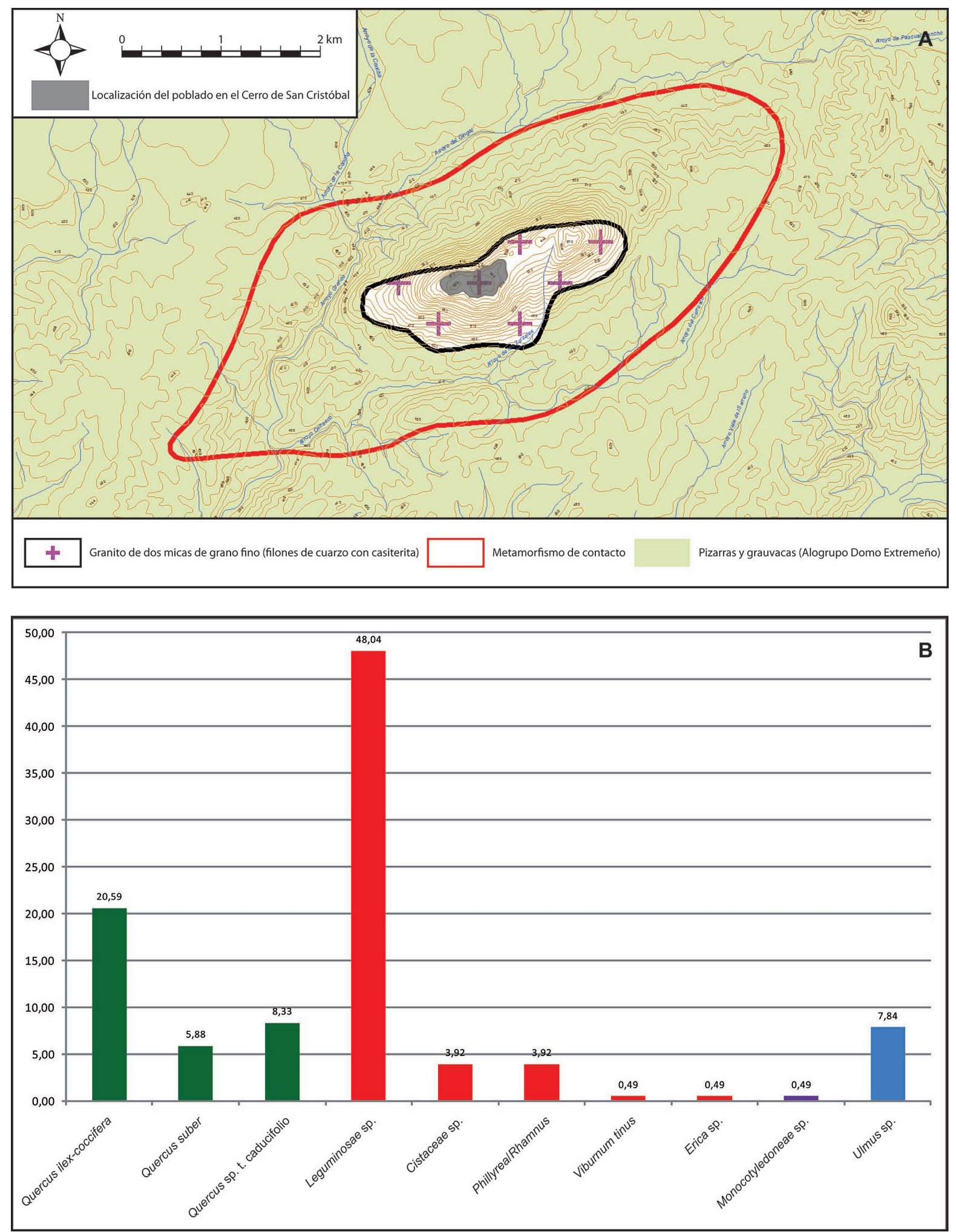

Fig. 2. A. Síntesis geológica de los entornos del Cerro de San Cristóbal de Logrosán (Cáceres); B. Datos antracológicos (David M. Duque Espino).

Trab. Prehist., 70, N. ${ }^{\circ}$ 1, enero-junio 2013, pp 95-113, ISSN: 0082-5638 doi: $10.3989 /$ tp.2013.12104 
Los recubrimientos coluviales terciarios-cuaternarios, presentes en la vertiente suroriental del cerro, y los aluviales cuaternarios, ajustados al estrecho cauce del arroyo del Gingal o Grande, son discretos y conectan Logrosán con la algo más extensa y fértil vega del río Ruecas, unos $7 \mathrm{~km}$ al Sur (Fig. 2A). La edafología dominante en estos entornos se caracteriza por suelos moderadamente ácidos, muy pobres en bases y con un contenido bajo en materia orgánica, lo que limita su uso a la alimentación del ganado en régimen de dehesa o mediante cultivos cerealistas para su consumo en verde (García Navarro 1995; García Navarro y López Piñeiro 2002).

Dicho potencial metalogenético y pecuario se puede correlacionar con el escaso registro arqueobotánico disponible de Logrosán (Hernández Carretero 2006). Este permite plantear la presencia de formaciones vegetales diversas, correspondientes a encinares, alcornocales, melojares y bosques ribereños integrados en un ambiente de transición meso-supramediterráneo, muy afectadas por la acción antrópica. Sus huellas parecen estar especialmente ligadas al propio asentamiento protohistórico y marcadas por el uso del fuego (microfósil no esporo-polínico Tipo 7A) (Fig. 2B). Probablemente la quema del monte debió tener como fin abrir los espacios forestados del cerro en aras de una mejor prospección, movilidad y explotación de los filones de la casiterita y, con ello, dar paso a los consecuentes procesos erosivos a escala local, como cabría inferir de la presencia del microfósil no esporo-polínico Tipo 207, propio de suelos de ladera con escasa cubierta vegetal, que se corresponden con el predominio de herbáceas y matorrales en las analíticas.

\subsection{Historia de la investigación}

El conocimiento de la arqueología protohistórica del Cerro de San Cristóbal es relativamente reciente, si bien su vinculación con Tartessos se remonta a hace más de cuatro décadas. Acaso por tener noticias del descubrimiento en 1950 de un importante yacimiento de estaño en esta localidad, o tal vez por saber de los hallazgos aislados que V. Sos Baynat (1977) publicaría posteriormente, J. M. Blázquez Martínez (1968: 49), en su célebre Tartessos y los orígenes de la colonización fenicia en Occidente, sugirió una relación que solo dos décadas después retomaría la investigación. Apuntó también allí cómo "Tartessos obtenía el estaño del río de su nombre que arrastraba el mineral del Mons Cassius, citado por Avieno (Ora Maritima: 259261) de zonas marginales a Tartessos, como posiblemente de la Extremadura española, de Logrosán y también de las proximidades de Cáceres, cuyas minas ya se aprovecharon a partir del Bronce I".

Más de dos décadas después, las prospecciones llevadas a cabo por Craig Merideth (1998a) en diversos yacimientos estanníferos del medio oeste peninsular (Salamanca, Beiras, Extremadura y Alentejo) volvieron a colocar la minería del Cerro de San Cristóbal en un horizonte investigador que, por la vía del estudio del poblamiento de final de la Edad del Bronce en Extremadura, también había llegado a Logrosán (Pavón Soldevila 1998). Advirtiendo las posibilidades de este yacimiento cacereño, entre 1992 y 1996 C. Merideth realizó una intensiva prospección arqueominera, orientada a conocer con precisión la distribución de las evidencias antiguas en superficie, las enormes alteraciones producidas por la explotación caótica de la casiterita entre 1950-1962 (Sos Baynat 1977: 261) y las zonas con mejores perspectivas para una ulterior excavación (Merideth 1998b). Esta última habría de desarrollarse finalmente en 1998 -primera campaña de excavaciones, y única publicada en detalle hasta ahora (Rodríguez Díaz et al. 2001)-, y en una serie ininterrumpida de trabajos entre 2000-2002 sobre cuyos resultados -ralentizados por el repentino fallecimiento de C. Merideth- se sintetizará algo en las páginas que siguen (2).

\section{LAS EXCAVACIONES (1998 Y 2000-2002) Y SUS RESULTADOS}

Los primeros trabajos de excavación, desarrollados por un equipo anglo-español del Institute of Archaeology, University College (Londres) (3) y del Área de Prehistoria de la Universidad de

(2) C. Merideth: Logrosán 2000. Excavation. 2nd september-25th september y Logrosán 2001. Excavation. 2nd september-25th september. Informes depositados en la Consejería de Educación y Cultura. Mérida, Badajoz.

(3) Craig Merideth, Brenda Craddock, Philip Andrews, Anthony Bridgeman y Anthony Gilmour.

Trab. Prehist., 70, N. ${ }^{\circ}$ 1, enero-junio 2013, pp 95-113, ISSN: 0082-5638 doi: 10.3989/tp.2013.12104 
Extremadura (4), se concentraron en el sector más occidental del cerro. Allí, la extensión de los indicios arqueológicos permitió definir una superficie ocupada de unas 7,5 ha, parcelada para su estudio en 8 sectores identificados con letras mayúsculas (A-H). Dicha extensión fue probablemente resultado de un crecimiento del poblado y/o de su relocalización en sentido NE-SO, que la estratigrafía horizontal tendió a corroborar. Las tareas arqueológicas entonces proyectadas, con un carácter eminentemente exploratorio, pretendieron valorar la ocupación protohistórica del sitio con el doble propósito de acotar temporalmente la explotación de la casiterita y calibrar sus relaciones interculturales en el contexto del occidente y mediodía peninsulares. Acorde con esos objetivos se primó un criterio estratigráfico. Por una parte, se hizo la limpieza-excavación de un par de bocaminas o trincheras de antigüedad a priori indefinida, que resultaban prometedoras por ofrecer indicios de explotación antigua en superficie (martillos fundamentalmente). Por otra parte, se sondearon distintos sectores del espacio parcelado.

Los trabajos centrados en las bocaminas (sobre todo las denominadas Minas A y B, en los sectores $\mathrm{H}$ y $\mathrm{B}$, respectivamente) no ofrecieron, sin embargo, resultados totalmente satisfactorios. En las catas efectuadas en ambas trincheras se constataron, efectivamente, fragmentos de vasijas cerámicas de fines de la Edad del Bronce y martillos de piedra prehistóricos, pero éstos aparecían casi siempre en contextos secundarios, posiblemente porque las actividades modernas, de quedar alguna traza de extracción antigua, la camuflaban e impedían su reconocimiento (Rodríguez Díaz et al. 2001: 85).

Casi todos los sondeos practicados fuera de dichas bocaminas mostraron una potencia arqueológica muy discreta y huellas, particularmente evidentes en el Corte 1, del fuerte proceso de arrasamiento sufrido a raíz de las labores mineras del siglo XX. Un Corte sobre el que hablaremos específicamente más adelante, por haberse realizado varias ampliaciones en las campañas de 2000 a 2002 y por su interés para los objetivos de este artículo.

Las excavaciones de los Cortes 2 y 3 (sectores E y F), por su parte, ofrecieron en los niveles de

(4) Alonso Rodríguez Díaz, Ignacio Pavón Soldevila y Jesús Mateos Donaire. base las evidencias más antiguas de ocupación del cerro (horizonte 'Logrosán I'). En el del Corte 2 (nivel II), una cata de 2 por $2 \mathrm{~m}$ ubicada hacia el sector central del poblado, se exhumaron los restos de varias vasijas cerámicas a mano, alguna decorada con motivos impresos de "punto en raya", acaso asociados a una posible subestructura. No muy distintas son las del mismo nivel II del Corte 3 , una cata que finalmente alcanzaría los 4 por $4 \mathrm{~m}$. Unos y otros materiales son de difícil adscripción, por su escasez, y plantean unos imprecisos antecedentes prehistóricos, posiblemente del Neolítico Final, en 'Logrosán I' (Rodríguez Díaz et al. 2001: 121-122).

Las primeras muestras relacionables con estructuras del Bronce Final-Orientalizante (horizonte 'Logrosán II') y con la actividad minera se hallaron en el nivel I del Corte 3 (Rodríguez Díaz et al. 2001: 52). Allí se documentó la ruina, muy mal conservada, de una zona de hábitat y trabajo. Consistía en dos tramos de piedras hincadas atribuidas a los restos de sendas cabañas de planta oval, en cuyo exterior se localizó in situ una concentración de material cerámico, algún martillo, varias molederas y un gran molino barquiforme volcado sobre uno de sus costados. Es ésta, sin duda, la pieza más interesante. La analítica de los microrrestos residuales en su superficie permitió excluir su vinculación con la molturación del cereal y, dados los valores de $\mathrm{Sn}, \mathrm{Cu}$ y $\mathrm{Pb}$, relacionarla con la trituración de minerales y, por ello, a un área funcional imbricada en el proceso productivo de la casiterita de Logrosán (Rodríguez Díaz et al. 2001: 168-169).

\subsection{Evidencias minero-metalúrgicas: 'rafa' y cabaña del Corte 1}

La tarea arqueológica mas destacable abordada en la segunda fase de los trabajos (2000-2002) ha sido la ampliación del Corte 1 , limitado a una cata inicial de 4,5 por $2 \mathrm{~m}$ y ubicado en una pequeña plataforma en el extremo suroccidental del subsector A de la cima. Ya en 1998, la excavación documentó una muy seria afectación de su mitad occidental por un pozo minero de los años 50-60, pero la mitad oriental reportó las primeras huellas de la actividad minera prehistórica de Logrosán. Allí, se constató una trinchera o 'rafa'

Trab. Prehist., 70, N. ${ }^{\circ}$ 1, enero-junio 2013, pp 95-113, ISSN: 0082-5638

doi: $10.3989 /$ tp.2013.12104 
con perfil en ' $\mathrm{U}$ ' de $0,70 \mathrm{~m}$ de ancho por 0,40 $\mathrm{m}$ de profundidad, completamente colmatada de tierra y restos de cuarzo machacado (nivel II), en cuyo fondo se observaban vetas de cuarzo con casiterita. Además, sus paredes laterales ofrecían marcas de las mazas de minero de piedra con que fue excavada. Otro estrato más reciente (nivel I) sellaba la trinchera y el relleno. Estaba constituido por una capa grisácea de tierra asociada a lo que se interpretó entonces como una porción de muro recto muy deteriorado. En dicha capa se recuperaron casi dos centenares de fragmentos cerámicos modelados característicos del Bronce Final, aunque de tipología ya evolucionada, y un interesante fragmento de crisol con mango perforado, próximo al tipo $\mathrm{H}$ de la clasificación de Tylecote (1976), con adherencias metalúrgicas (Rodríguez Díaz et al. 2001: 17).

La expectativa despertada por estos últimos hallazgos motivó la ulterior ampliación del Corte 1 en varias direcciones, deparando las mayores novedades de las campañas 2000-2002. Podemos avanzar el descubrimiento de los restos, muy deteriorados pero reconocibles, de una cabaña de planta oval y una posible zona exterior de actividad metalúrgica. Dicha cabaña, orientada NE$\mathrm{SO}$, está delimitada por un perímetro de lastras o piedras hincadas, y mide $6,80 \mathrm{~m}$ en sentido longitudinal y 4,40 m de anchura máxima. Ofrece una entrada por el $\mathrm{SO}$, precedida de un pavimento exterior de piedras correspondiente a los vestigios considerados como restos de un muro en 1998. En ello, se reconoce un paralelismo con el prototipo de vivienda característico del tránsito Bronce Final-Orientalizante en el sur peninsular, incluida la región extremeña (Izquierdo de Montes 1998; Enríquez Navascués et al. 2001; Rodríguez Díaz et al. 2001: 124-125; Delgado Hervás 2005). En posición descentrada se localizaron un hogar $\mathrm{y}$ varios 'pies de poste', así como dos concentraciones de cuarzo machacado. Estos últimos indicios son coherentes con los restos materiales allí recuperados (cerámicas, machacadores de piedra $\mathrm{y}$ algunos fragmentos de molinos barquiformes), con las prácticas de trituración y molturación referidas a propósito de la evidencia del Corte 3, y con el relleno, por desechos de trabajo similares, de la 'rafa' de base amortizada y excavada en el Corte 1 en 1998. En la zona exterior de dicha cabaña se documentaron un hogar y un posible horno (así identificados por B. Craddock en su

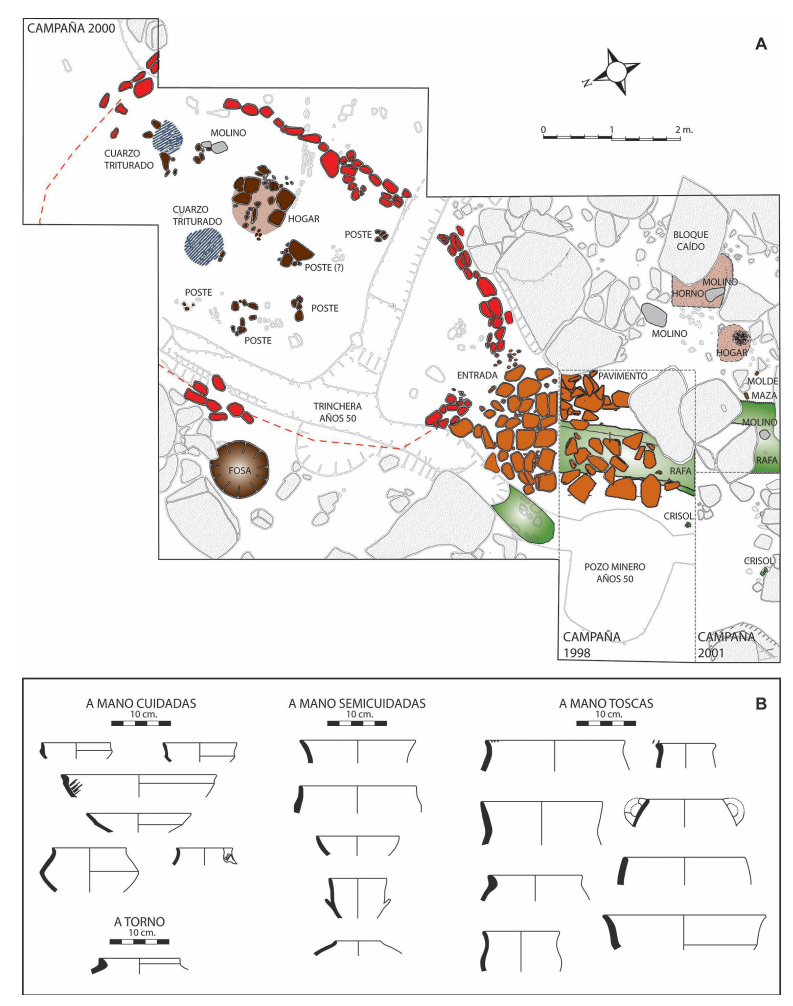

Fig. 3. A. Planimetría de la cabaña del Corte 1 (elaboración propia a partir de B. Craddock); B. Tipología básica de materiales cerámicos del Cerro de San Cristóbal de Logrosán.

planimetría), estructuras en cuyas inmediaciones se recogieron un molino, un crisol hemisférico y un molde (Fig. 3A).

\subsection{Cronología}

La intensa actividad minero-metalúrgica de este asentamiento está constatada empíricamente. Cabe ahora sopesar las posibilidades ofrecidas por la cultura material, y la cerámica en particular, para afinar la cronología de la explotación, primer paso para esbozar en qué contexto sociocultural y económico situarla. Las producciones cerámicas son mayoritariamente modeladas a mano, incluyendo desde las que ofrecen aspecto cuidado hasta las toscas que son estadísticamente dominantes (Rodríguez Díaz et al. 2001: 125-132).

Tal vez las más sugerentes, desde el punto de vista morfológico, sean las primeras, con aca- 
bados oscuros y bruñidos o espatulados de aspecto cuasi metálico. Corresponden sobre todo a cuencos, copas o cazuelas de perfiles carenados. Los primeros se suelen vincular a otros similares documentados en yacimientos del Bronce Final Atlántico que permiten situar el origen de este poblado minero hacia comienzos del siglo VIII a.C., si bien la tendencia creciente en la bibliografía (Vilaça 1995: 375; Berrocal Rangel y Silva 2010: 136-137) es a fecharlas en el siglo IX o incluso antes (sin calibrar). Las copas y cazuelas responden a perfiles, tanto arcaizantes como evolucionados, muy frecuentes en el ámbito cultural tartésico (Ruiz Mata 1995). Dichos materiales sitúan a Logrosán en la órbita de la primera gran cultura protohistórica del Suroeste, marcando una fase de eclosión del poblado durante los siglos VIII-VII a.C. Ollas y vasos de diverso perfil son, por otro lado, las formas dominantes entre las medianamente cuidadas. Las toscas, de pastas muy poco depuradas, suelen pertenecer a ollas y vasos de paredes entrantes, con superficies principalmente alisadas, a veces escobilladas e incluso tratamiento diferencial (bruñido-rugoso). Ambas familias resultan poco sensibles a la matización cronológica. En las escasas cerámicas a torno de la muestra, destaca un eximio repertorio anfórico de inspiración fenicia o más propiamente meridional, suficiente para extender la cronología de la ocupación hasta finales del siglo VII-comienzos del siglo VI a.C. (Fig. 3B). Menos precisos en su temporalidad, pero especialmente elocuentes por su funcionalidad (Hunt Ortiz 2003), son los restos de molinos barquiformes, martillos-mazas, percutores... recuperados en los cortes excavados y en superficie. La cultura material, en su conjunto, refleja bien el contexto funcional y el ambiente atlántico-mediterráneo/tartésico en que se desenvolvió este enclave.

\section{EL PROCESO MINERO- METALÚRGICO DE LA CASITERITA EN LOGROSÁN Y EL EJE 'LOGROSÁN-MEDELLÍN'}

La información arqueológica y arqueominera disponible hasta ahora permitiría ofrecer una propuesta del proceso minero-metalúrgico de la casiterita en Logrosán en época tartésica (Fig. 4).
Dicho proceso es una verdadera 'cadena operativa' minero-metalúrgica, en parte avanzada por C. Merideth (Rodríguez Díaz et al. 2001: 33), que futuros trabajos deberán perfilar aún más tanto arqueológica como analíticamente. Se iniciaría con la apertura de trincheras o 'rafas' con martillosmazas de piedra (Fig. 5: 1), siguiendo los filones de cuarzo (que albergan la mineralización de casiterita y encajan en la roca granítica) probablemente visibles en superficie. Es una técnica minera de tradición prehistórica, que no exige otros trabajos de acondicionamiento, y que está en consonancia con las modalidades extractivas empleadas en la Baja Andalucía para el beneficio de los carbonatos de cobre superficiales, como el de la conocida mina onubense de Chinflón (Pellicer Catalán y Hurtado Pérez 1980; Hunt Ortiz 2003: 68-74). Diversos autores han situado el máximo florecimiento de Chinflón y otras minas bajoandaluzas

\section{PROPUESTA DEL PROCESO MINERO-METALÚRGICO DE LA CASITERITA}

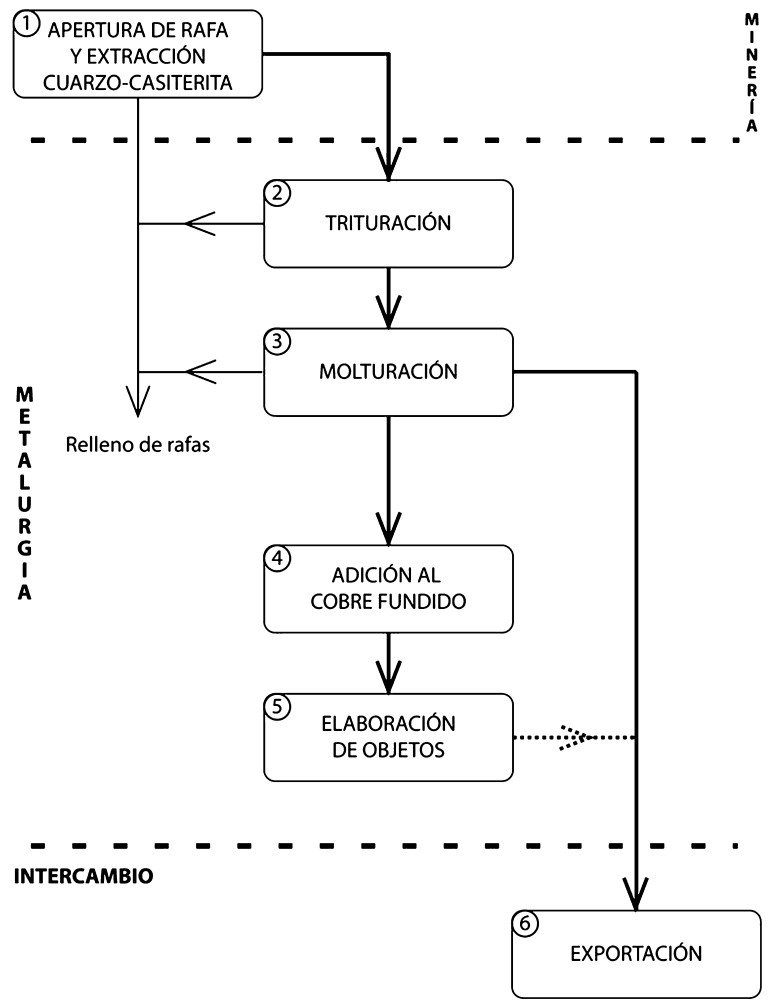

Fig. 4. Propuesta de la 'cadena operativa' de la casiterita en el poblado minero-metalúrgico del Cerro de San Cristóbal de Logrosán (Cáceres) a partir de los hallazgos de las campañas 1998 y 2000-2002. Se fecha en la transición Bronce Final-Orientalizante. 


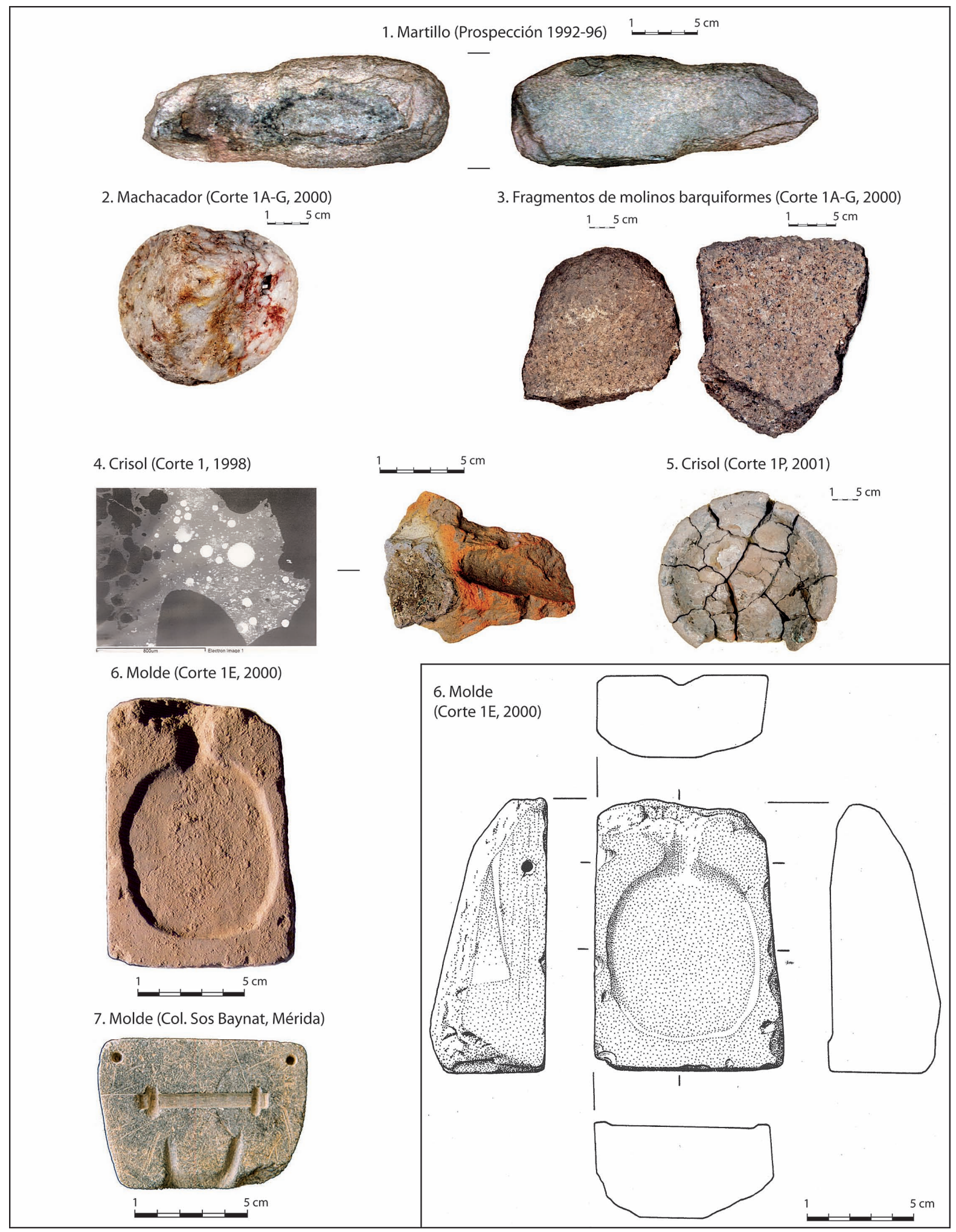

Fig. 5. Tecnología relacionada con la obtención y procesado de la casiterita en el poblado minero-metalúrgico del Cerro de San Cra (Cáceres). Se fecha en la transición Bronce Final-Orientalizante (fotos: C. Merideth; dibujo B. Craddock). 
durante el Bronce Final, por carecer de elementos de filiación fenicia, sugiriéndose una posible explotación hasta el siglo VII a.C., o incluso no más allá del siglo VIII a.C. (Ruiz Mata 1989: 218; Pérez Macías 1996). La originalidad de Logrosán radica en que constatamos esta modalidad de trabajo asociada a la casiterita, y desde un momento también relativamente antiguo.

A esta exigente tarea extractiva seguiría, en un segundo paso, la trituración del cuarzo con machacadores de piedra (Fig. 5: 2) a fin de extraer la casiterita, tal y como sugieren los detritos documentados en el interior de dicha cabaña. En un tercer momento, tendría lugar su separación, afinado y la molturación en los molinos barquiformes, documentados en la cabaña del Corte 1 (Fig. 5: 3) y en el espacio de trabajo al exterior de las cabañas del Corte 3. Los subproductos o residuos generados se emplearían para la amortización o relleno de las 'rafas' ya agotadas o abandonadas.

Tras un último afinado, si fuera preciso y a tenor del registro exterior de la citada cabaña del Corte 1, la casiterita finamente molida se añadiría directamente al cobre 'prefundido o fundido' en pequeños crisoles de barro (Fig. 5: 4-5), según se desprende de las analíticas realizadas por C. Merideth del ejemplar descubierto en 1998 (Rodríguez Díaz et al. 2001: 29-42) (Fig. 5: 4). Esta técnica, simple en extremo, de añadir casiterita molida fue detectada por el propio Merideth (1998a: 158-160) en crisoles aparecidos en el poblado del Bronce Final de Alegríos, Portugal, $\mathrm{y}$ en el edificio postorientalizante de La Mata de Campanario (Rodríguez Díaz y Ortiz Romero 1998: 214). No obstante, parece que también se empleó en la producción de bronce detectada en lugares más alejados de las fuentes minerales, como en El Carambolo (Hunt Ortiz et al. 2010: 280). El cobre indistintamente pudo provenir de vetas no lejanas a San Cristóbal (Locutura Rupérez y Alcalde Molero 2006) o de lingotes plano-convexos similares acaso a los fragmentos encontrados en el poblado sincrónico de El Risco de Sierra de Fuentes (Gómez Ramos y Rovira Lloréns 2001: 197). Tampoco debe descartarse la reutilización de los abundantes objetos inservibles, verdadera chatarra, constatados en superficie y en excavación; un proceso que, tras dos o tres refundiciones, requiere nuevas cantidades de estaño. Sin que podamos asegurarlo, el procesa- miento de estos elementos en general bien pudo realizarse en estructuras de combustión como las detectadas alrededor de la cabaña del Corte 1 (5). Este aspecto exige un mayor volumen de información arqueológica y de contrastación analítica en el futuro, dadas las diversas formas de efectuar la llamada 'aleación reina' cobre-estaño (cementación de granalla de cobre con casiterita, aleación de metales y la co-reducción de minerales de cobre y casiterita) planteadas por la investigación arqueometalúrgica y experimental (Rovira Lloréns 2007: 21-22).

El paso siguiente, y final, de esta 'cadena operativa' admite la doble posibilidad de la elaboración de piezas en moldes de piedra y la salida del mineral. La producción de objetos metálicos en Logrosán está atestiguada también en el Corte 1 . De allí procede un fragmento de molde de piedra para la fabricación de hachas y 'discos' (?) (Fig. 5: 6). El negativo del hacha se define en un lateral del molde, cuya rotura impide precisar la tipología concreta de la pieza más allá de su genérica adscripción a los ejemplares propios del Bronce Final. Aunque afectada también por la fractura de uno de sus extremos, la cara interna del molde muestra el negativo de una pieza discoidal, de escaso grosor y con un canal distal o proximal, según sea orientada (6). A partir de la fotografía conservada, el diámetro estimado del disco estaría entre 7-8 cm, su espesor alrededor de $2 \mathrm{~mm}$ y la anchura del canalillo en torno a 2 $\mathrm{cm}$. Tipológicamente, dicha pieza se aproxima a las referidas por A. M. Rauret (1976: láms. XIX y XXI) como "moldes para hebillas de cinturón y discos" y a otra estudiada por P. Moret et al. procedente de Tossal de Montañés (siglo VI a.C.) relacionada con la fabricación de espejos (Moret et al. 2006: 58, figs. 47 y 48). Aunque en nuestro caso esta última valoración podría apoyarse en las representaciones de espejos de algunas estelas de guerrero (Celestino Pérez 2001: 165, fig. 33) o en el espejo de bronce del tesoro de Aliseda (Almagro Gorbea 1977: 215), resulta difícil asumirla sin incertidumbre a tenor del reducido diámetro del disco resultante y la probable función

(5) No obstante, en el informe de la excavación de 2000, estas estructuras se describen como "hogar" y "horno para cereales" (Cortes 1E y 1G).

(6) Según consta en el informe de la campaña de 2000, esta pieza fue llevada a Londres para su análisis. Lamentablemente aún no ha sido localizada y depositada en el Museo de Cáceres. 
del canalillo más como conducto de llenado del molde que como enmangue del espejo. Sea como fuere, tales impresiones quedan supeditadas a un estudio directo de la pieza, hoy por hoy, imposible de realizar. A todo ello cabría añadir un molde para barritas/escoplos de la 'colección Sos Baynat' (Fig. 5: 7), amén de numerosos fragmentos metálicos de cronología diversa (punzones, escoplos, hachas, puntas....), en su mayoría bronces binarios y algunos plomados (Sos Baynat 1977; Merideth 1998b: 87-96).

A partir de dicha información resulta difícil determinar la escala y finalidad de la producción de bronces en Logrosán. Poco podemos aportar si se trata de piezas destinadas al consumo interno del poblado o si algunas estuvieron concebidas para el intercambio comarcal o interregional, como sugiere el molde para la fabricación de hachas y 'discos' (?). Tampoco se puede descartar que ciertos metales llegaran como chatarra a Logrosán para ser refundidos (vide supra). Al margen de los elementos elaborados en este enclave, intuimos que la mayor parte de la casiterita de Logrosán debió ser exportada en función de la ausencia, hasta el momento, de escorias y hornos de fundición claramente relacionados con la reducción del mineral a gran escala. No obstante, como se ha reconocido antes, tal ausencia de escorias no debe cerrar del todo la puerta a otras posibles formas de obtención de estaño dada la escasa superficie excavada y la considerable extensión del asentamiento.

La salida del mineral (y quizá de algunos objetos metálicos) de Logrosán, por cuestiones estrictamente geográficas (Sos Baynat 1977: 277), sería hacia el valle medio del Guadiana siguiendo el curso del Ruecas. El Cerro de San Cristóbal está en un verdadero 'fondo de saco' conformado por los montes de Villuercas, que hacen casi inviables las conexiones hacia el Norte. El Ruecas, que nace cerca de Cañamero y desemboca en el Guadiana no lejos de Medellín, se perfila como la ruta preferente, por no decir la única, para el trasiego de la casiterita de San Cristóbal. Ello posibilita relacionar la arqueología protohistórica de Logrosán con la de las Vegas Altas y, en última instancia, con la del Suroeste tartésico. Pese a todo, esta vía de salida natural de la casiterita hacia el mediodía peninsular exige mayores niveles de información arqueológica y arqueográfica sobre cuestiones esenciales como la caracterización del poblamiento protohistórico de dicho eje 'Logrosán-Medellín' o las relaciones de dependencia/interdependencia entre ambos núcleos (Fig. 6).

\subsection{Los posibles ejes 'Aliseda-Badajoz' $y$ 'Montánchez-Alange'}

La distribución macroespacial del poblamiento conocido del Bronce Final-Orientalizante extremeño, y su relación con recursos potenciales y cursos fluviales, nos sugirió hace algún tiempo la posibilidad de proyectar esquemas similares a los del modelo 'Logrosán-Medellín', a los ejes 'Aliseda-Badajoz' y 'Montánchez-Alange' a través de los cursos del Gévora-Zapatón y Aljucén, respectivamente. Las ocupaciones protohistóricas de dichas zonas del Tajo y del Guadiana son conocidas desde hace años. Están especialmente bien documentadas las de la Sierra del Aljibe de Aliseda, El Risco de Sierra de Fuentes y Montánchez, en la penillanura cacereña, y las del Cerro del Castillo de Alange y La Muela-Alcazaba en Badajoz, ambas controladoras de estratégicos pasos del Guadiana (Pavón Soldevila 1998; Enríquez Navascués et al. 1998; Rodríguez Díaz y Pavón Soldevila 1999; Enríquez Navascués et al. 2001) (Fig. 6).

Somos plenamente conscientes de las características y condicionantes de la información metalogenética disponible, producto en gran medida de estrategias recientes de búsquedas y beneficio industrial. Sin embargo, dicha hipótesis de trabajo ha sido sopesada de forma preliminar a través de una selectiva prospección geológica y arqueominera del sector central de la penillanura cacereña, integrada en el proyecto El Tiempo del Tesoro de Aliseda y autorizada por la Consejería de Educación y Cultura del Gobierno de Extremadura. La exploración se llevó a cabo entre junio-julio de 2011 y tuvo como objetivo general valorar la posible explotación protohistórica de los indicios mineros de estaño, plata y hierro ( $\mathrm{Sn}, \mathrm{Ag}$ y Fe) del triángulo 'Aliseda-Sierra de Fuentes-Casas de Don Antonio’ (Fig. 7). Se pretendía, así mismo, calibrar la posible relación de dicho potencial minero-metalúrgico con el poblamiento protohistórico de la zona en vías de estudio con centro en Aliseda y, por ende, la contextualización de la 


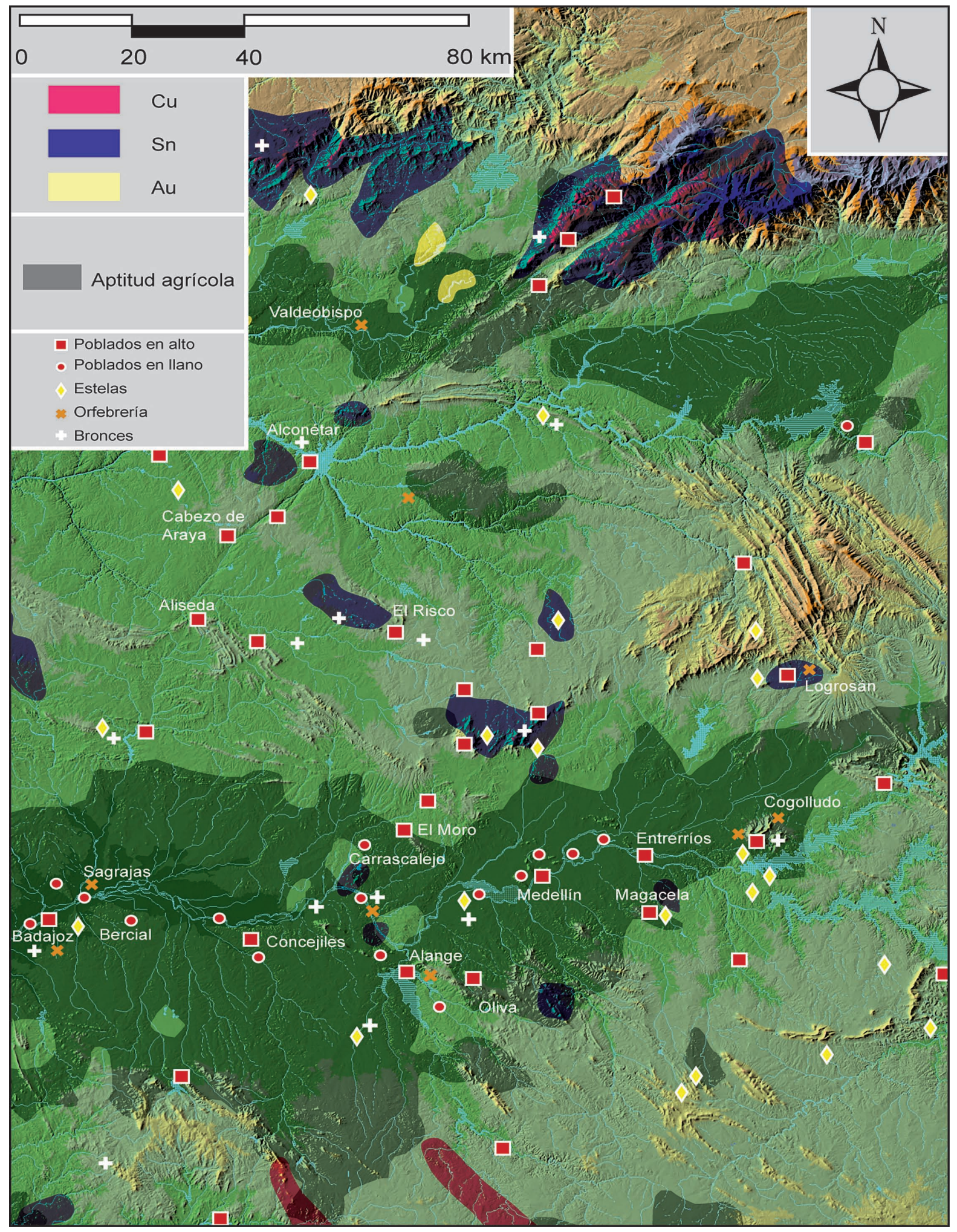

Fig. 6. Poblamiento y hallazgos diversos del periodo Bronce Final-Orientalizante en las cuencas extremeñas del Tajo y Guadiana (occidente de la Península Ibérica).

Trab. Prehist., 70, N. ${ }^{\circ}$ 1, enero-junio 2013, pp 95-113, ISSN: 0082-5638 doi: $10.3989 /$ tp.2013.12104 


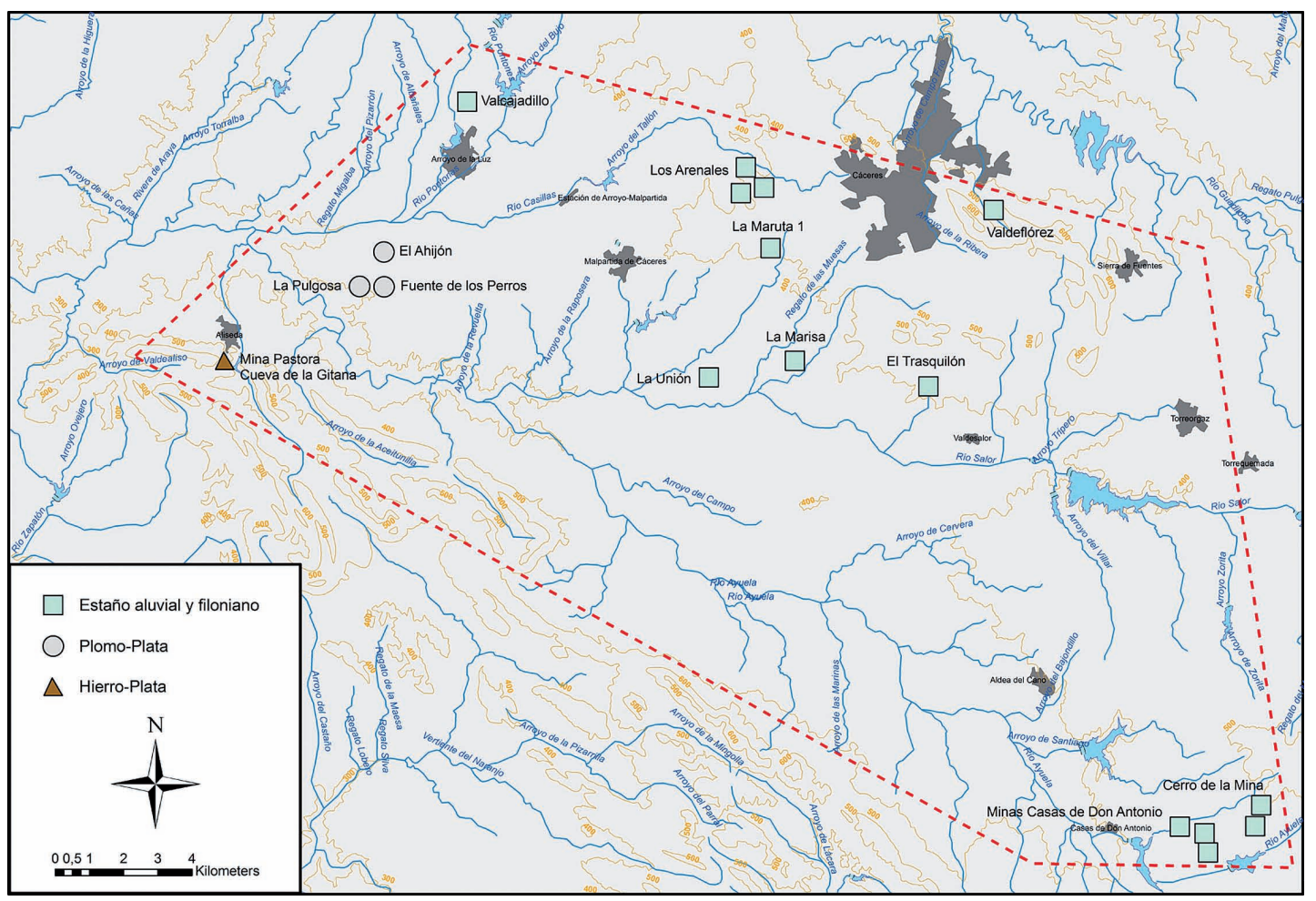

Fig. 7. Indicios metalogenéticos prospectados en 2011, en la penillanura cacereña (occidente de la Península Ibérica).

explotación de casiterita del Cerro de San Cristóbal de Logrosán (Cáceres) (7).

La metodología de los trabajos realizados contempló, en términos generales, los protocolos y tareas habituales de este tipo de actuación (Hunt Ortiz 1996). Los criterios que han dirigido esta intervención pueden resumirse en los siguientes: 1) recopilación de los indicios mineros incluidos en los mapas metalogenéticos y geológicos de Cáceres y Extremadura (Locutura Rupérez y Alcalde Molero 2006, 2007; Mapa Geológico Nacional, hojas 1:50.000, núm. 703, 704 y 729; 2) recogida de noticias y de trabajos arqueomineros previos (Domergue 1987; Merideth 1998a, 1998b); y 3) rastreo de los topónimos que pudieran indicar otros indicios y, en particular, aquéllos no contemplados en los trabajos estrictamente geológicos o

(7) Rodríguez Díaz, A.; Pavón, I.; Duque, D. M.; Ponce de León, M. y Hunt, M.: Informe sobre la prospección geológica y arqueominera en la penillanura cacereña (junio-julio de 2011). Depositado en la Consejería de Educación y Cultura del Gobierno de Extremadura. Diciembre de 2011. mineros. En todos los sitios prospectados se siguió el mismo procedimiento: a) identificación del indicio geológico portador de la mineralización y su caracterización geológico-minera así como su extensión y límites; y b) exploración sistemática de la zona del indicio y su entorno a fin de comprobar la existencia o no de utensilios de explotación o de enriquecimiento de menas, tales como mazas, martillos, fragmentos de cerámica...

Como se ha dicho, en los registros mineros seleccionados interesaban los metales de estaño, plomo, por su relación con el beneficio de plata, y hierro, por él mismo y como eventual portador de plata. Los principales sitios prospectados relacionados con el laboreo aluvial y filoniano del estaño fueron Valcajadillo (Arroyo de la Luz), Los Arenales, La Maruta-1, El Trasquilón, La Unión, La Marisa y Valdeflórez (Cáceres); Casas de Don Antonio y Cerros de la Mina (Montánchez). Los indicios de plata reconocidos fueron los de $\mathrm{La}$ Pulgosa, Fuente del Perro y El Ahijón (Cáceres). El único registro de hierro visitado fue el de la mina de La Pastora (Aliseda), recientemente mu- 
sealizada por el Gobierno de Extremadura y localizada justo en la vertiente opuesta del poblado protohistórico de la Sierra del Aljibe (Rebollada Casado et al. 2010) (Fig. 7).

Tras el análisis de cada uno de los indicios prospectados podemos señalar, en términos generales, su escaso potencial arqueominero. Los registros estanníferos más importantes explorados, Los Arenales, El Trasquilón-La Unión y Valdeflórez, han sido objeto de explotación en tiempos recientes lo que dificulta la identificación de labores antiguas, si las hubiera habido. En sus entornos sólo se encontraron esporádicos rastros arqueológicos de épocas diversas, como hachas talladas, algunos percutores en cuarcita armoricana, fragmentos de molinos barquiformes o de rotación en granito... Sin embargo, no se documentaron trazas claras ni útiles (mazas, percutores...) que pudieran sugerir un trabajo antiguo de laboreo y concentración de menas de casiterita. Los resultados obtenidos en los indicios de plata y hierro prospectados son similares. Todos ellos parecen exploraciones y explotaciones recientes, salvo quizá la mina La Pastora de Aliseda, si se confirma la cronología antigua (romana/protohistórica) de las escorias de derretido de hierro documentadas de forma abundante junto a la galería de La Gitana (8).

En función de lo antedicho, y en particular respecto a la posible explotación protohistórica de la casiterita en el sector centro-occidental de la penillanura cacereña, muy poco puede aportarse por el momento a la hipotética existencia de los referidos ejes 'Aliseda-Badajoz' y 'Montánchez-Alange'. No obstante, recordaremos que los trabajos son solo una primera aproximación a un potencial minero-metalúrgico incontestable, enmarcado en un paisaje profundamente alterado por las labores modernas, sobre el que la investigación futura deberá insistir con estrategias y formas de análisis quizá más afinadas.

(8) Las escorias, sin formar acumulaciones, se extienden por una amplia zona. Presentan los típicos cordones de derretido, sin mucho grosor $(c a .2 \mathrm{~cm})$ y fragmentadas $(<10 \mathrm{~cm})$. El análisis de FRX de una de las muestras confirma que es escoria de hierro. Un argumento de su probable antigüedad sería la falta de actividad metalúrgica en este lugar durante su explotación moderna. Así mismo, podría aludirse a la presencia de algunas cerámicas a mano en esta misma zona que exigirían una mayor atención en el futuro. Por último, la siderurgia fue documentada en los niveles postorientalizantes y romano-republicanos de la Sierra del Aljibe, situados justamente en la ladera opuesta de esta elevación (Rovira Lloréns y Gómez Ramos 1999).

\section{EL POBLADO MINERO-METALÚRGICO DE SAN CRISTÓBAL DE LOGROSÁN Y LA PERIFERIA TARTÉSICA}

Actualmente barajamos dos posibles modelos teóricos, el 'de comunidades de paso' y el de los 'puntos de comercio', para explicar los mecanismos del traslado del mineral-metal desde los centros productivos del Tajo al Guadiana y Suroeste peninsular, en particular para el posible eje 'Logrosán-Medellín' y con mayor incertidumbre para los de 'Aliseda-Badajoz' y 'Montánchez-Alange'. $\mathrm{Ni}$ contamos con estudios arqueométricos específicos, ni olvidamos las limitaciones de los estudios isotópicos y de los elementos traza del estaño para rastrear procedencias y relaciones a media-larga distancia (Rovira Lloréns 2007: 24). Pese a ello, nos parece que la más que probable salida de esta producción minera (y quizá metalúrgica) debió efectuarse, al menos en un primer momento, en un marco de articulación espacial asimilable al denominado 'de comunidades de paso', comparable, a grandes rasgos, al que ha trazado R. Vilaça (1995: 412) en la geografía también estannífera de la Beira Interior. En él, la red tejida por una confederación de jefaturas individualistas, comunidades de igual rango, situadas entre puntos nodales de una estructura política descentralizada según la propuesta trasmitida por K. Kristiansen (2001: 96), controlarían estratégicamente las rutas de intercambio pero no los territorios fuera de ellas. Una red que operativamente requiere un cierto grado de estabilidad poblacional, como el ya constatado en el Bronce Final extremeño, que haría posible la circulación de la casiterita y/o los objetos de bronce (Pavón Soldevila y Rodríguez Díaz 2007: 18).

No pocos investigadores han asumido el valor de algunos bienes, en particular joyas áureas y objetos de bronce, como elementos que aportan el prestigio necesario para cimentar las relaciones sociales entre las élites del final de la Edad del Bronce. No solo han situado su nivel funcional más destacable en el intercambio de dones y la creación de alianzas por vía matrimonial, sino que también han encontrado en las estelas diademadas y de guerreros o extremeñas su ámbito de plasmación icónica más sugestivo (Ruiz-Gálvez Priego 1992: 238). En Las Villuercas la estela de guerrero más afamada es la de Solana de Cabañas (Roso de Luna 1898). Pero, además de ésta, justo es reconocer el gran interés de los dos ejemplares 
aparecidos en Logrosán (Celestino Pérez 2001: 350-351) y más por su cercanía al poblado minero-metalúrgico del Cerro de San Cristóbal que por razones estéticas. Su estado incompleto es notorio, pero la expresividad de dichos monolitos es coherente con el discurso elitista de los grupos sociales implicados en la producción, trasiego y gestión de los recursos interiores entre los que, vistos los valores imperantes en la época, sin duda se encontraría el citado mineral. También, por restringirnos a ítems de esta misma comarca, el célebre tesoro de Berzocana (Almagro Gorbea 1977: 22-24) redunda en la idea del protagonismo de las élites rurales en la explotación de los recursos y, en paralelo, sobre la consolidación de las jefaturas o de una cierta forma de 'señorialización latente', en un marco político marcadamente heterárquico (Rodríguez Díaz 2009: 62-70).

Se responsabiliza, directa o indirectamente, a la llegada de los colonizadores fenicios al mediodía y occidente hispano de una serie de innovaciones tecnológicas y transformaciones sociopolíticas de hondo calado, cuyo reflujo se adivina incluso en escenarios tan interiores como Extremadura. De su mano, p. ej., se produce tanto la incorporación a la Edad del Hierro como la aceleración del proceso de complejidad social que se vislumbra tras la consolidación de las jefaturas previas. Sin embargo, como muy acertadamente en nuestra opinión ha subrayado S. Rovira Lloréns (1993: 46), la llegada del hierro no representó la crisis del bronce como aleación metálica, sino una especie de relanzamiento, ahora al servicio de los nuevos requerimientos de una sociedad emergente. En su opinión, los anteriores monopolios relacionados con el bronce, en especial los de materias primas tales como el estaño, periclitaron o perdieron su peso político entrando en una dinámica económica en la que la explotación de los recursos se orientaba más hacia el comercio y los mercados que hacia el control estratégico. Hoy por hoy, no sabemos hasta qué punto dicha coyuntura tuvo su reflejo en Logrosán pero, teóricamente, esa clave mercantilista bien pudo haber acentuado las relaciones entre este poblado, ya en una fase avanzada de su secuencia (Rodríguez Díaz 2009: 55-57), y alguno de los estratégicos asentamientos del valle medio del Guadiana.

Como algunos autores han apuntado (Aubet Semmler 1990: 33, 2000: 32), la adecuada satisfacción de la demanda de materias primas por parte de los fenicios habría requerido la complicidad pactada de una sociedad autóctona ya en vías de complejidad y la adecuada infraestructura que brindaban los canales tradicionales de intercambio. No obstante, la nueva escala de dichas transacciones, próxima ya a la de esquemas mercantiles, habría propiciado la conversión de algunas de las iniciales 'comunidades de paso' en verdaderos 'puntos de comercio'. En el estado actual de conocimientos, insistimos, Medellín es el máximo candidato a mercado de las producciones logrosaniegas, como sugeriría la vinculación entre ambos enclaves, a través del curso del Ruecas. También lo hacen la propia ubicación de Medellín, junto a uno de los vados históricos del Guadiana, y su propio crecimiento protourbano (Almagro Gorbea y Martín Bravo 1994; Almagro Gorbea et al. 2008). Un crecimiento impulsado a partir de un momento dado por la riqueza de la vega, como se ha reflejado, ya en época orientalizante, en el espejo de la colonización agraria de su territorio (Rodríguez Díaz et al. 2009), pero que en origen seguramente estuvo insuflado por el mercadeo del mineral/metal. Su crecimiento junto al Guadiana originaría, hacia el siglo VII a.C., atractivos y hasta ahora inéditos procesos de territorialización y jerarquización documentados arqueológicamente.

Precisamente, no pocos estudios sobre la Prehistoria Reciente y la Protohistoria han reconocido el teórico papel de los núcleos protourbanos, o las ciudades, como importadores y distribuidores de algunos productos en tránsito. Resultaría posible conceder este rol, visto su desarrollo, a sitios que, como Aliseda, Medellín o Badajoz, cabe calificar de focos de primer orden en la periferia de Tartessos. En lo que a la prehistoria del metal se refiere, la concepción de Extremadura como una realidad periférica y fronteriza que hemos sostenido en otras ocasiones (Rodríguez Díaz y Enríquez Navascués 2001) también es un modelo de interpretación viable. Es sobradamente conocido el importante papel concedido a la minería, especialmente de la plata y del cobre (Fernández Jurado 1993; Pérez Macías 1996), como factor de desarrollo en la civilización tartésica pero no lo es menos la carencia de estaño, fundamental para alear bronce, en el subsuelo de la Andalucía occidental. En perspectiva, cabe considerar a Extremadura, reserva económica de Tartessos, como su más cercano punto de abastecimiento de 
casiterita. Así lo han venido sugiriendo tanto la geografía como el reflejo tardío de dicha interacción en los textos clásicos.

Hace ya tres décadas, en un estudio sobre el comercio atlántico del estaño en época orientalizante, J. Alvar Ezquerra (1980: 47-48), basándose esencialmente en las fuentes grecolatinas y algunos datos arqueológicos, apuntaba la necesidad de contemplar la existencia de rutas terrestres, y no solo marítimas como las tradicionalmente vinculadas a los mercaderes fenicios, para la captación y el traslado del estaño interior hacia el mediodía. En su opinión, los gaditanos del Período Orientalizante no tenían necesidad de alargar sus viajes marítimos hasta la Bretaña francesa o Cornualles, pues en un tiempo mucho más breve podían encontrar tanto estaño como les era necesario. No obstante, cabía conceder el máximo protagonismo a la iniciativa tartésica en la estructuración de dichas rutas terrestres, pese a acabar desembocando e imbricándose en el mercado fenicio. Ese sentido se podría conferir, al menos, a sendos pasajes de la Ora Maritima de Avieno y de la Orbis Descriptio de Pseudo-Scimno (González de Canales 2004: 262), que vienen a expresar que el río Tartessos arrastraba el estaño desde la 'Céltica', es decir, desde los territorios interiores. Como tantos otros textos, no han sido inmunes a la discusión historiográfica, respecto al uso inadecuado del término 'estaño' cuando realmente se quería aludir a la plata (González de Canales 2004: 295 y 298). Hoy día la arqueología nos permite situar la discusión en otros términos. La localización de una lámina de estaño en contextos precoloniales de Huelva (anteriores a c. 760 a.C.) (González de Canales et al. 2004: 150-151) unida, por supuesto, a la propia evidencia del poblado minero-metalúrgico de San Cristóbal de Logrosán permiten hacernos dudar del matiz meramente simbólico atribuido a esos antiguos pasajes literarios. El contundente hallazgo de más de 200 lingotes de estaño, de origen aún no definido, en el pecio fenicio del Bajo de la Campana (Cartagena, Murcia) (siglo VII a.C.) (9) (Mederos Martín y Ruiz Cabrero 2004: 269), se sumaría a estas evidencias para dar verosimilitud a una explotación, extensa en el tiempo y diversificada espacialmente en los distintos episodios

(9) http://www.simplynetworking.es/news-3508-31-bajo_ de_la_campana_the_important_phoenician_boat_excavation_ at_la_manga.html (consulta 30-VII-2011). de su cadena productiva-comercial, que acabaría integrándose en los circuitos mercantes fenicios.

En nuestros días, se está construyendo una nueva visión de Tartessos. La valoración de su civilización desde planteamientos más integradores permite liberar a los modelos 'Centro-Periferia' de las connotaciones rígidamente difusionistas, cuyas primeras aplicaciones en ocasiones arrastraban, y facilitar en cierto modo la relectura de procesos de interacción que, como los orbitados en torno al estaño, ofrecen un gran atractivo. Tampoco resultan ajenos a esta visión los nuevos planteamientos interpretativos, nacidos de la reflexión sobre la naturaleza de los espacios periféricos. Sirva mencionar la progresiva definición de la 'zona simbiótica' extremeña desde la que, desde hace algún tiempo, venimos trabajando (Pavón Soldevila 1999: 207-208; Rodríguez y Enríquez 2001) y en particular la de la interacción entre las tierras del Guadiana y la penillanura cacereña. Estas perspectivas reconocen una iniciativa cada vez mayor a los contingentes humanos del Suroeste interior. Desde ellas sugerimos la plena integración de la actual Extremadura en Tartessos y su identificación como una periferia dinámica, creativa y original en sus desarrollos ulteriores. Los procesos de fondo y los detalles materiales que subyacen tras ellos así lo demuestran. Una simple muestra, en este sentido, es el reconocimiento de algo tan periférico como las mismas estelas extremeñas, en los últimos tiempos, como propiamente 'estelas de Tartessos' (Celestino Pérez y López Ruiz 2006).

\section{AGRADECIMIENTOS}

Este trabajo se integra en el proyecto HAR201014917 "El tiempo del tesoro de Aliseda" del Plan Nacional $\mathrm{I}+\mathrm{D}+\mathrm{i}$ del MICINN, http://www.eltiempodeltesorodealiseda.com (consulta 9-XI-2012).

\section{BIBLIOGRAFÍA}

Almagro Gorbea, M. 1977: El Bronce Final y el Periodo Orientalizante en Extremadura. Bibliotheca Praehistorica Hispana XIV, CSIC. Madrid. 
Almagro Gorbea, M.; Lorrio, A. J.; Mederos, A. y Torres, M. 2008: "La ciudad-estado de MedellínConisturgis y la Cuenca del Guadiana en el Período Orientalizante". En M. Almagro Gorbea (ed.): La necrópolis de Medellín. III Estudio analiticos. IV Interpretación de la necrópolis. V El marco histórico de Medellín-Conisturgis. Bibliotheca Archaeologica Hispana 26 (3). Real Academia de la Historia. Madrid: $1.033-1.059$.

Almagro Gorbea, M. y Martín Bravo, A. M. 1994: "Medellín 1991. La ladera norte del Cerro del Castillo”. En M. Almagro Gorbea y A. Martín Bravo (eds.): Castros y oppida en Extremadura. Complutum Extra 4, Universidad Complutense. Madrid: 77-128.

Alvar Ezquerra, J. 1980: "El comercio del estaño atlántico durante el período orientalizante". Formas de intercambio durante la Antigüedad: actas del coloquio. Memorias de Historia Antigua 4: 43-50.

Aubet Semmler, M. E. 1990: "El impacto fenicio en el interior del mediodía peninsular”. En A. Velázquez, J. L. de la Barrera y J. J. Enríquez (eds.): La cultura tartésica y Extremadura. Cuadernos Emeritenses 2, Museo Nacional de Arte Romano. Mérida: 29-44.

Aubet Semmler, M. E. 2000: "Cádiz y el comercio atlántico". Actas del IV Congreso Internacional de Estudios Fenicios y Púnicos (Cádiz 1995) I: 31-41. Cádiz.

Berrocal Rangel, L. y Silva, A. C. 2010: O castro dos Ratinhos (Barragem do Alqueva, Moura), Excavaçôes num povoado proto-histórico do Guadiana, 2004-2007. O Arqueólogo Português, Suplemento 6. Lisboa.

Blázquez Martínez, J. M. 1968: Tartessos y los orígenes de la colonización fenicia en Occidente. Ediciones de la Universidad de Salamanca. Salamanca.

Celestino Pérez, S. 2001: Estelas de guerrero y estelas diademadas. La precolonización y formación del mundo tartésico. Bellaterra Arqueología. Barcelona.

Celestino Pérez, S. y López Ruiz, C. 2006: "New light on the warrior stelae from Tartessos (Spain)". Antiquity 80: 89-101.

Chicharro, E.; Boixereu, E.; Villaseca, C. y LópezGarcía, J. A. 2011: "Contribución a la puesta en valor del patrimonio geológico y minero del Geoparque de Las Villuercas: el Cerro de San Cristóbal (Logrosán, Cáceres)". De Re Metallica 17: 47-54.

Delgado Hervás, A. 2005: "La transformación de la arquitectura residencial en Andalucía occidental durante el Orientalizante: una lectura social". En S. Celestino y J. Jiménez (eds.): El Período Orientalizante. Actas del III Simposio Internacional de Arqueología de Mérida: Protohistoria del Mediterráneo Occidental I, Anejos del Archivo Español de Arqueología XXXV: 585-594.

Domergue, C. 1987: Catalogue des Mines et des Fonderies Antiques de la Péninsule Ibérique. Publications de la Casa de Velásquez, Archéologie VIII, De Boccard. Paris.
Enríquez Navascués, J. J.; Rodríguez, A. y Pavón, I. 2001: El Risco. Excavación de urgencia en Sierra de Fuentes (Cáceres). 1991 y 1993. Memorias de Arqueología Extremeña 13, Consejería de Cultura de la Junta de Extremadura. Cáceres.

Enríquez Navascués, J. J.; Valdés, F.; Pavón, I.; Rodríguez, A. y López, P. 1998: "La estratigrafía del Sector Puerta de Carros-2 (SPC-2) de Badajoz y el contexto poblacional del Valle Medio del Guadiana en la Edad del Hierro". En A. Rodríguez Díaz (ed.): Extremadura Protohistórica: Paleoambiente, Economía y Poblamiento. Servicio de Publicaciones de la Universidad de Extremadura. Cáceres: 157-199.

Fernández Jurado, J. 1993: "Plata y plomo en el comercio fenicio-tartesio". En R. Arana Castillo, A. M. Muñoz, S. Ramallo y M. M. Ros (eds.): Metalurgia en la Península Ibérica durante el primer milenio a.C. Estado actual de la investigación. Universidad de Murcia. Murcia: 131-165.

Florido Laraña, P. (ed.) 1987: La minería en Extremadura. Junta de Extremadura. Mérida.

García Navarro, A. 1995: "Los suelos". En J. A. Devesa Alcaraz (ed.): Vegetación y flora de Extremadura. Badajoz: 49-78.

García Navarro, A. y López Piñeiro, A. 2002: Mapa de suelos de la provincia de Cáceres. Escala1:300.000. Publicaciones de la Universidad de Extremadura. Cáceres.

Giumlia-Mair, A. y Lo Schiavo, F. 2003: Le problème de l'étain à l'origine de la métallurgie. Actes du XIVème Congrès UISPP (Liège, Belgique 2001). British Archaeological Reports International Series 1199, Archaeopress. Oxford.

Gómez Ramos, P. y Rovira Lloréns, S. 2001: “Aspectos metalúrgicos de El Risco y de El Torrejón de Abajo". En J. J. Enríquez Navascués, A. Rodríguez e I. Pavón: El Risco. Excavaciones de urgencia en Sierra de Fuentes (Cáceres). 1991 y 1993. Memorias de Arqueología Extremeña 4. Cáceres: 195-213.

González de Canales Cerisola, F. 2004: Del Occidente mítico griego a Tarsis-Tarteso. Fuentes escritas y documentación arqueológica. Biblioteca Nueva. Madrid.

González de Canales Cerisola, F.; Serrano, L. y Llompart, J. 2004: El emporio fenicio precolonial de Huelva (ca. 900-770 a.C.). Biblioteca Nueva. Madrid.

Gumiel, P. y Arribas, A. 1990: “Metallogeny”. En R. D. Dalmeyer y E. Martínez García (eds.): Pre-Mesozoic Geology of Iberia. Springer Verlag. Berlin: 212-219.

Hernández Carretero, A. M. 2006: "El paisaje del Tajo extremeño en el Período Orientalizante. Estudio paleoambiental". En J. Jiménez Ávila (ed.): El conjunto orientalizante de Talavera la Vieja (Cáceres). Memorias del Museo de Cáceres 5. Cáceres: 45-61.

Hunt Ortiz, M. A. 1996: "Prospección arqueológica de carácter minero y metalúrgico: fuentes y restos". Acontia. Revista de Arqueología 2: 19-28. 
Hunt Ortiz, M. A. 2003: Prehistoric Mining and Metallurgy in South West Iberian Peninsula. British Archaeological Reports, International Series 1188. Archaeopress. Oxford.

Hunt Ortiz, M. A.; Montero, I.; Rovira, S.; Fernández, A. y Rodríguez, A. 2010: "Estudio arqueométrico del registro de carácter metálico y metalúrgico de las campañas 2002-2005 en el yacimiento de El Carambolo (Camas, Sevilla)". En M. de la Bandera Romero y E. Ferrer Albelda (eds.): El Carambolo. 50 años de un tesoro. Universidad de Sevilla. Sevilla: 271-295.

Izquierdo de Montes, R. 1998: “La cabaña circular en el mundo tartésico. Consideraciones sobre su uso como indicador étnico". Zephyrus 51: 277-288.

Kristiansen, K. 2001: Europa antes de la Historia. Península. Barcelona.

Locutura Rupérez, J. y Alcalde Molero, C. (eds.) 2006: Mapa Metalogenético de la provincia de Cáceres. Escala 1:200.000. Ministerio de Educación y Ciencia-Instituto Geológico y Minero de España y Junta de Extremadura. Madrid.

Locutura Rupérez, J. y Alcalde Molero, C. (eds.) 2007: Mapa Metalogenético de Extremadura a escala 1:250.000. Ministerio de Educación y CienciaInstituto Geológico y Minero de España y Junta de Extremadura. Madrid.

Luzón Nogué, J. M. 1983: "Algunos aspectos de la minería antigua en Galicia”. En G. Pereira Menaut (ed.): Estudos de Cultura Castrexa e de Historia Antiga de Galicia. Limiar. Homenaxe a D. F. López Cuevillas e a D. R. Otero Pedrayo. Universidade de Santiago de Compostela. Santiago de Compostela: 213-224.

Mederos Martín, A. y Ruiz Cabrero, L. A. 2004: “El pecio fenicio del Bajo de La Campana (Murcia, España) y el comercio del marfil norteafricano". Zephyrus 57: 263-281.

Merideth, C. 1998a: An Archaeometallurgical Survey for Ancient Tin Mines and Smelting Sites in Spain and Portugal, 1990-1995. British Archaeological Reports, International Series 714, Archaeopress. Oxford.

Merideth, C. 1998b: "El factor minero: el caso del estaño y el poblado de Logrosán (Cáceres)". En A. Rodríguez Díaz (ed.): Extremadura Protohistórica: Paleoambiente, Economía y Poblamiento. Servicio de Publicaciones de la Universidad de Extremadura. Cáceres: 73-96.

Montero Ruiz, I. 2010: "Minería y metalurgia en la investigación prehistórica”. En I. Montero (ed.): Manual de Arqueometalurgia. Cursos de formación permanente para arqueólogos 1, Museo Arqueológico Regional de la Comunidad de Madrid y Sección de Arqueología del CDL de Madrid. Madrid: 53-86.

Moreno, F.; Matas J.; Leyva, F.; Díez, A.; Fuente, J. V. de la; Carrasco, A. y Gutiérrez J. C. 2004: Mapa Geológico de España, Escala 1:50.000, Nacional,
Hoja núm. 732 /14-29, Valdecaballeros. Instituto Geológico y Minero de España. Madrid.

Moret, P., Benavente, J. A. y Gorgues, A. 2006: Iberos del Matarraña. Investigaciones arqueológicas en Valdeltormo, Calaceite, Cretas y La Fresneda (Teruel). Taller de Arqueología de Alcañiz y Casa de Velázquez. Alcañiz (Teruel).

Pavón Soldevila, I. 1998: El tránsito del II al I milenio a.C. en las cuencas medias de los ríos Tajo y Guadiana: La Edad del Bronce. Servicio de Publicaciones de la Universidad de Extremadura. Cáceres.

Pavón Soldevila, I. 1999: "Los albores de la protohistoria en la mesopotamía extremeña: notas para la discusión de un modelo". Estudos Pré-Históricos VII: 179-212.

Pavón Soldevila, I. y Rodríguez Díaz, A. 2007: “Campo y ciudad en la protohistoria extremeña: conceptos y criterios investigadores". En A. Rodríguez Díaz e I. Pavón Soldevila (eds.): Arqueología de la tierra. Paisajes rurales de la protohistoria peninsular. Servicio de Publicaciones de la Universidad de Extremadura. Cáceres: 11-44.

Pellicer Catalán, M. y Hurtado Pérez, V. 1980: El poblado metalúrgico de Chinflón. Publicaciones del Departamento de Prehistoria y Arqueología. Universidad de Sevilla. Sevilla.

Pérez Macías, J. A. 1996: Metalurgia extractiva prerromana en Huelva. Servicio de Publicaciones de la Universidad de Huelva. Huelva.

Rauret Dalmau, A. M. 1976: La metalurgia del bronce en la Península Ibérica durante la Edad del Hierro. Instituto de Arqueología y Prehistoria. Universidad de Barcelona. Barcelona.

Rebollada Casado, E.; Arias, M. y Gumiel, P. 2010: Mina Pastora (Aliseda, Cáceres): Contribución al desarrollo del patrimonio geológico-minero de Extremadura. Universidad de Huelva. Huelva.

Rodríguez Díaz, A. 2009: Campesinos y "señores del campo". Tierra y poder en la protohistoria extremeña. Bellaterra Arqueología. Barcelona.

Rodríguez Díaz, A.; Duque, D. M. y Pavón, I. 2009: El caserio de Cerro Manzanillo (Villar de Rena, Badajoz) y la colonización agraria orientalizante en el Guadiana Medio. Memorias de Arqueología Extremeña 12, Consejería de Cultura y Turismo, Junta de Extremadura. Mérida.

Rodríguez Díaz, A. y Enríquez Navascués, J. J. 2001: Extremadura tartésica. Arqueología de un proceso periférico. Bellaterra Arqueología. Barcelona.

Rodríguez Díaz, A. y Ortiz Romero, P. 1998: “La Mata de Campanario (Badajoz): un nuevo ejemplo de arquitectura de prestigio en la Cuenca Media del Guadiana". En A. Rodríguez Díaz (ed.): Extremadura Protohistórica: Paleoambiente, Economía y Poblamiento. Servicio de Publicaciones de la Universidad de Extremadura. Cáceres: 201-246.

Rodríguez Díaz, A. y Pavón Soldevila, I. 1999: El poblado protohistórico de Aliseda (Cáceres). Cam-

Trab. Prehist., 70, N. ${ }^{\circ}$ 1, enero-junio 2013, pp 95-113, ISSN: 0082-5638

doi: $10.3989 /$ tp.2013.12104 
paña de 1995. Consejería de Cultura de la Junta de Extremadura, Ayuntamiento de Aliseda. MéridaAliseda.

Rodríguez Díaz, A.; Pavón, I.; Merideth, C. y Juan, J. 2001: El Cerro de San Cristóbal, Logrosán, Extremadura, Spain. The archaeometallurgical excavation of a Late Bronze Age tin-mining and metalworking site. British Archaeological Reports, International Series 922, Archaeopress. Oxford.

Roso de Luna, M. 1898: "Lápida sepulcral de Solana de Cabañas, en el partido judicial de Logrosán (Cáceres)". Boletín de la Real Academia de la Historia XXXII-XXXIII: 179-182.

Rossi, Ph. 1975: Géologie et gitologie du Cerro San Cristobal, Logrosán, Cáceres, Espagne. Thèse Laboratoire de géologie structurale et appliquée d'Orsay, Université de Paris Sud. Orsay.

Rovira Lloréns, S. 1993: "La metalurgia de la Edad del Hierro en la Península Ibérica: una síntesis introductoria”. En R. Arana Castillo, A. M. Muñoz, S. Ramallo y M. M. Ros (eds.): Metalurgia en la Península Ibérica durante el primer milenio a.C. Estado actual de la investigación. Universidad de Murcia. Murcia: 45-70.

Rovira Lloréns, S. 2007: "La producción de bronces en la Prehistoria". En J. Molera, J. Farjas, P. Roura y T. Pradell (eds.): Avances en Arqueometría 2005. Actas del VI Congreso Ibérico de Arqueometría (Girona 2005): 21-35. Girona.

Rovira Lloréns, S. y Gómez Ramos, P. 1999: “Arqueometalurgia del hierro de época orientalizante y tardo-republicana en Aliseda (Cáceres)". En A. Rodríguez Díaz e I. Pavón Soldevila: El poblado protohistórico de Aliseda (Cáceres). Campaña de 1995. Consejería de Cultura de la Junta de Extremadura y Ayuntamiento de Aliseda. Mérida-Aliseda: 220-233.
Rovira Lloréns, S. y Montero Ruiz, I. 2003: "Natural Tin-Bronze Alloy in Iberian Peninsula Metallurgy: Potentiality and Reality". En A. Giumlia-Mair y F. Lo Schiavo (ed.): Le problème de l'étain à l'origine de la métallurgie. Actes du XIVème Congrès UISPP (Liège, Belgique 2001). British Archaeological Reports International Series 1199, Archaeopress. Oxford: 15-22.

Rovira Lloréns, S. y Renzi, M. 2010: “Las operaciones pirometalúrgicas y sus subproductos". En I. Montero (ed.): Manual de Arqueometalurgia. Cursos de formación permanente para arqueólogos 1 . Museo Arqueológico Regional de la Comunidad de Madrid y Sección de Arqueología del CDL de Madrid. Madrid: 87-122.

Ruiz-Gálvez Priego 1992: "La novia vendida: orfebrería, herencia y agricultura". Spal 1: 219-251.

Ruiz Mata, D. 1989: "Huelva. Un foco temprano de actividad metalúrgica durante el Bronce Final". En M. E. Aubet Semmler (ed.): Tartessos. Arqueología protohistórica del Bajo Guadalquivir. Ausa. Sabadell: 209-243.

Ruiz Mata, D. 1995: "Las cerámicas del Bronce Final. Un soporte tipológico para determinar el tiempo y el espacio tartésico". En D. Ruiz Mata (ed.): Tartessos 25 años después. 1968-1993. Jerez de la Frontera. Actas del Congreso conmemorativo del V Symposium Internacional de Prehistoria Peninsular: 265313. Jerez de la Frontera.

Sos Baynat, V. 1977: "Los hallazgos prehistóricos de Logrosán (Cáceres)". Revista de Estudios Extremenos XXXIII-2: 261-286.

Tylecote, R. F. 1976: A history of metallurgy. Metals Society. Londres.

Vilaça, R. 1995: Aspectos do povoamento da Beira Interior (Centro e Sul) nos finais da Idade do Bronze. Trabalhos de Arqueologia 9, Instituto Portugués do Patrimonio Arquitectónico. Lisboa. 